NASZA DERMATOLOGIA Online OUR DERMATOLOGY Online

Source of Support: Nil

Competing Interests: None

\section{THE COMPARISON STUDY OF 5 FLUOROURACIL VS. CRYOTHERPY IN THE TREATMENT OF THE BACKHAND RESISTANT COMMON WART}

\author{
Rahim Asghariazar ${ }^{1}$, Hamideh Herizchi Ghadim ${ }^{1}$, \\ Shahla Babaeinezhad ${ }^{2}$, Sina Nobahari ${ }^{2}$
}

${ }^{\text {I} D e r m a t o l o g y ~ D e p a r t m e n t, ~ S i n a ~ H o s p i t a l, ~ F a c u l t y ~ o f ~ M e d i c i n e, ~ T a b r i z ~ U n i v e r s i t y ~ o f ~}$ Medical Sciences, Tabriz, Iran

${ }^{2}$ Member of scientific association of Islamic Azad University, Tabriz branch-Iran, Medical faculty, Tabriz, Iran

Corresponding author: Dr. Rahim Asghariazar

dr.asghariazar@gmail.com

\begin{abstract}
Introduction: Wart is a common disease which is caused by a group of viruses called Human Papilloma Virus. The most prevalent type of wart is common wart and the most prevalent site of involvement is hands. Complete recovery, no recurrency and effectiveness in all patients are not obtained by any of therapeutic methods, so in this study we decided to compare therapeutic effects of 5 Fluorouracil (FU) with cryotherapy in treatment of common warts of backhand.

Material and Methods: In this study, in a one year period from March 2012 to March 2013, 60 patients that referred to dermatology clinic of Sina hospital included the study with the diagnosis of backhand wart .Patients were divided into two groups of treatment, one treated with cryotherapy (30 patients) and one threated with $5 \mathrm{FU}$ (30 patients). Age and gender of patients, number of lesions and duration of involvement were documented. Treatment by topical 5 FU was implemented for 4 weeks, twice a day for 4 hours each course. Second group was treated by cryotherapy (liquid nitrogen spray, two sessions with a two-week interval between sessions). Their response to treatment was evaluated as good, moderate and weak.

Results: There was no difference in age, gender and mean of duration of involvement and number of lesions between two groups. Response to treatment was considerably better in $5 \mathrm{FU}$ group $(\mathrm{p}=0.02)$. Also rate of relapse and complications were lower in $5 \mathrm{FU}$ group of treatment, with a statistically significant difference compared to the cryotherapy group $(\mathrm{P}<0.001)$. In separate evaluation of complications only scar formation was equal in two groups and pain and bullae formation were lower in $5 \mathrm{FU}$ group with a statistically significant difference $(\mathrm{P}<0.001$ both).

Conclusions: According to limited studies in this field, results of this study could be the base of more comprehensive studies in evaluating the efficacy of $5 \mathrm{FU}$ in treatment of common warts. Appropriate therapeutic response in addition to lower rates of relapse and complications by 5 FU treatments can make a major change and lower the psychosocial burden of this disease dramatically.
\end{abstract}

Key words: Fluorouracil; Cryotherapy; Resistant warts of backhand

Cite this article:

Asghari Azar R, Herizchi H, Babayi Nejad Sh, Nobahari S. The comparison study of 5 Fluorouracil vs. cryotherpy in the treatment of the backhand resistant common wart. Our Dermatol Online. 2014; 5(3): 258-260.

\section{Introduction}

Warts are fleshy tumors/lumps that grow on the hands and feet, but it may grow on all parts of the body. They are indeed benign prolife ration of skin and mucous [1-5]. This disease is relatively common and it caused by a group of viruses called "human papilloma virus", that can grow on the skin, the inner surface of the mouth and genital and anal areas $[6,7]$

According to importance of performance, availability and cost of selected method in tearing patients with "hand warts", and also the lack of relevant studies about this case $(8,9)$, we decided to compare"5-fluorouracil therapy" with "cryotherapy" in treatment of common warts on hands, if there is one superior to the other methods, we use it as the preferred treatment method.

\section{Materials and Methods}

Is this study during the one- year period (1391-1392), 60 patients with "hand warts" referred to the dermatology clinic in Sina Hospital, were selected for the study. Patients were treated in two categories (30 of them with cryotherapy and 30 with 5-fluorouracil) 
Age and sex, number of warts, and duration of illness were registered in patient's history. Treatment with local 5-flurorouracil was carried out for 4 hours at 2 times / day for 4 weeks.

The patients were taught how to use the cream and then, they use the cream themselves. The second group treated by cry therapy with liquid nitrogen and using spray cryotherapy with a distance of 1-2 cm from the warts in the term of 20-30 seconds depending on the size of warts, to the extent that white halo is formed around the wart.

\section{Results}

In our study there were $28(46.7 \%)$ female individuals and also $32(53.3 \%)$ male participants. Average age of all participants was $17.61 \pm 8.35$ years. The youngest was 6 and the oldest one was 48 years old. Average number of warts were $4.73 \pm 2.73(3-20)$ also duration time to warts were $14.95 \pm 9.55$. response to medication in 26 individuals were good $(43.3 \%)$ in 22 cases were moderate $(36.7 \%)$ and in 12 cases were low (20\%). Response to medication was analyzed between two groups and results proved that 5 -fu had a significant different to cryoteraphy group $(p=0.02)$. We had compare also side effects of two methods as a due it shows that side effect in 5-fu group were significantly lower than cryoteraphy group $(p<0.001)$. In $19(63.3 \%)$ cases in cryoteraphy group pain was reported as side effects but noun of participants in 5-fu show any pain. which was significantly difference between two groups. Scorch reported in $22(37.3 \%)$ in cryotraphy and 0 in 5-Fu also in this point of view there were a significant difference between two groups.

\section{Discussion}

This study is a randomized clinical trial that carried out with the aim of comparing the two methods, "using local 5-FU" and "Cryotherapy" in response to the treatment, medical complications and recurrence of common hand warts. In this illness, 60 patients were divided into two therapeutic groups, and were evaluated in a prospective study.

In our survey, overall, $53 / 3 \%$ of patients were male. $(63 / 3 \%$ in 5 -FU group and $43 / 3 \%$ in cryotherapy group, $\mathrm{P}=0 / 72$ ) and the mean age of patients in both groups were respectively $19 / 2 \pm$ $10 / 02$ and $15 / 96 \pm 5 / 94(\mathrm{P}=0 / 13)$. The mean duration of illness in 5 -FU group, was slightly significant $(16 / 47 \pm 9 / 42$ in comparison to $13 / 48 \pm 3 / 48, \mathrm{P}=0 / 27)$. Average number of warts was similar in the two groups. $(4 / 53 \pm 3 / 12 \mathrm{~m} 5$-FU group in comparison to $4 / 93 \pm 2 / 3$ in Cryotherapy group $\mathrm{P}=0 / 57$ )

Unlike previous studies $[10,11]$, most of our patients were male and mean age of patients was lower compared to previous results. This issue can be caused from epidemiological differences of disease in various locations. The mean duration of illness in Luk et al Survey was about 17-19 months and similar to our study [7]. This value in Valikhani et al study was approximately 30 months and much higher than in our study [11]. Unlike general impression that skin wart is a simple disease with an outpatient and fast treatment, our survey along with other studies shows that many patients are already infected and are trying to treat it. In addition to this issue, such high figures associated with disease duration, notes the importance of effective treatment with low recurrence. Average number of lesions in our study was lower than Valikhani and Sayad Rezayi's [11]

In our study, the therapeutic response of 5-FU group was much better than Cryotherapy (60\% positive response in 5-FU group in comparison to $26 / 7 \%$ positive response in Cryotherapy group, $\mathrm{P}=0 / 02$ ). Disease recurrence and also complications was lower in 5-FU group, and the difference of these cases with Cryotherapy group was statistically meaningful.

In the separately assessment of treatment effects, having scars was the only effect in 5-FU group that was equal with Cryotherapy group. Having pain (0 in comparison 63/3\%) and blisters ( 0 in comparison $37 / 3 \%$ ) was rarely seen in this group, this case has also a significant difference with Cryotherapy group. And the cure rate was 30 and $42 / 5 \%(\mathrm{P}=0 / 02)$

Also side effects and pain were seen in 27, 19 patient receiving both Cryotherapy and F-U, and 14, 11 patient receiving Cryotherapy and placebo. These differences were not statistically significant. In Valikhani, survey [11], 93/3\% of patients in the group treated with Cryotherapy had complete recovery, whereas the complete recovery was seen $66 / 7 \%$ of patients treated with 5 -FU $(\mathrm{P}=0 / 02)$

However in both these studies, clinical improvement was higher in Cryotherapy group, they recommended using 5-FU for certain categories of patients.

Again in Sayad Rezayi, study, however the outcome was more favorable in Cryotherapy group but the difference is not too much $(52 \%$ positive response in 5 -FU group and $60 \%$ in Cryotherapy group), disease recurrence in 5-FU group was lower like our study ( $8 \%$ in comparison to $18 \%$ ). Unlike our survey, noun of the patients in this study had been scars, and the amount of pain and blisters in the Cryotherapy group of patients was very high, while in 5-FU group were not reported It seems that according to the results of studies conducted by Hursthouse et al [12] and Lee aet al [13], we can consider 5-FU as an appropriate treatment for hand warts.

\section{Conclusion}

This study prove the usage of 5-Fu in warts treatment which were significantly low in side effects and reliable in treatment, it would one of basic studies to investigate more about 5-Fu.

\section{Acknowledgments}

We would like to thank the Sina Hospital mangers especially dermatology department for their contribution in the clinical measurements and data collection. We also thank all the participants of this clinical trial.

\section{REFERENCES}

1. Sterling JC, Handfield-Jones S, Hudson PM. British Association of Dermatologists. Guidelines for the management of cutaneeous wart. Br J Dermatol. 2001;144:4-11.

2. Gibbs S, Harvey I, Sterling JC, Stark R.. Local treatments for cutaneous warts. Cochrane Database Syst Rev. 2003;3:CD001781.

3. BerthJones J, Bourke J, Eglitis H, Harper C, Kirk P, Pavord S, et al. Value of a second freezethaw cycle in cryotherapy of common warts. Br J Dermatol. 1994;131:8836.

4. Connolly M, Basmi K, O'Connell M, Lyons JF, Bourke JF. Cryotherapy of warts: a sustained 10 s freeze is more effective than the traditional method. Br J Dermatol. 2001;145:5547

5. Choi JW, Cho S, Lee JH. Does immunotherapy of viral warts provide beneficial effects when it is combined with conventional therapy? Ann Dermatol. 2011;23:282-7. 
6. Kwok CS, Holland R, Gibbs S. Efficacy of topical treatments for cutaneous warts: a meta-analysis and pooled analysis of randomized controlled trials. Br J Dermatol. 2011;165:33-246.

7. Luk NM, Tang WY, Tang NL, Chan SW, Wong JK, Hon KL, et al. Topical 5-fluorouracil has no additional benefit in treating common warts with cryotherapy: a single-centre, double-blind, randomized, placebo-controlled trial. Clin Exp Dermatol. 2006;31:394-7.

8. Smolinski KN, Yan AC. How and when to treat molluscum contagiosum and warts in children. Pediatr Ann. 2005;34:211-221.

9. Zamiri M, Gupta G. Plantar warts treated with an immune response modifier: a report of two cases. Clin Exp Dermatol. 2003;28 Suppl $1: 45-7$.

10. Luk NM, Tang WYM, Tang NSL, Chan SW, Wong JK, Hon $\mathrm{KL}$, et al. Topical 5-fluorouracil has no additional benefit in treating common warts with cryotherapy: a single-centre, doubleblind, randomized, placebo-controlled trial. Clin Exp Dermatol. 2006;31:394-7.
11. Krawtchenko N, Roewert-Huber J, Ulrich M, Mann I, Sterry W, Stockfleth E. A randomised study of topical 5\% imiquimod vs. topical 5 -fluorouracil vs. cryosurgery in immunocompetent patients with actinic keratoses: a comparison of clinical and histological outcomes including 1-year follow-up. Br J Dermatol. 2007;157 Suppl 2:34-40. 12. Hursthouse M. Treatment of wart with 5-Fluorouracil. Br J Dermatol. 1970;83:216-22.

13. Lee S, Kim JG, Chun SI. Treatment of Verruca plana with $5 \%$ 5-FIuorouraciI Ointment. Derma tologica. 1980;160:383-9. 